\title{
Sleep disturbances in caregivers of patients with advanced cancer: A systematic review.
}

\author{
Kirstin F. Maltby, G.D.P.S., M.SC.MED., ${ }^{1,2}$ \\ Christine R. Sanderson, M.P.H., F.R.A.C.P., ${ }^{1,2,3}$ \\ Elizabeth A. Lobb, M.APP.SCI., PH.D., ${ }^{1,2,4}$ \\ Jane L. Phillips, R.N., B.Sc., PH.D. ${ }^{5}$
}

\begin{abstract}
${ }^{1}$ School of Medicine, The University of Notre Dame Australia, Darlinghurst, New South Wales, Australia
${ }^{2}$ Calvary Health Care Sydney, Kogarah, New South Wales, Australia

${ }^{3}$ CareSearch Palliative Care Knowledge Network, Department of Palliative and Supportive Services, Flinders University, Bedford Park, South Australia, Australia

${ }^{4}$ Cunningham Centre for Palliative Care, Darlinghurst, New South Wales, Australia

${ }^{5}$ The Centre for Cardiovascular and Chronic Care, University of Technology Sydney, Faculty of Health, Ultimo, New South Wales, Australia
\end{abstract}

\section{ABSTRACT}

Objective: Sleep disturbances are a common issue for those who provide informal care to someone with a life-limiting condition. The negative consequences of poor sleep are well documented. The purpose of the present study was to determine the sleep patterns of caregivers of patients with advanced cancer.

Method: An extensive systematic review of studies reporting empirical sleep data was undertaken in 2015 in accordance with the PRISMA Statement. A total of eight electronic databases were searched, with no date restrictions imposed. Additionally, a search of the bibliographies of the studies identified during the electronic search was conducted. Search terms included: "sleep," "insomnia," "sleep disturbance," "circadian rhythm," "caregiver," "carer," "advanced cancer," "palliative cancer," and MESH suggestions. The inclusion criteria required studies to be in English and to report primary qualitative and/or quantitative research that examined sleep in caregivers of patients with advanced cancer. Unpublished studies, conference papers, and dissertations were excluded.

Results: Overall, 10 studies met the inclusion criteria and were included in the review. Two major findings emerged from the data synthesis. First, at least $72 \%$ of caregivers reported moderate to severe sleep disturbance as measured by the Pittsburgh Sleep Quality Index.

Second, objective measurement of caregivers' sleep identified that some caregivers experienced up to a $44 \%$ reduction in their total sleep time compared to the recommended eight hours.

Significance of Results: Reduction in total sleep time appears to be the biggest issue facing caregivers' sleep. Future studies need to explore the specific factors that cause these sleep disturbances and thus help to identify interventions to optimize sleep. 


\section{INTRODUCTION}

Sleep is a vital and complex process, with adequate restorative sleep being essential for optimal health and well-being. Sleep disturbances appear to be a common phenomenon experienced by the friends, family, or partners who provide unpaid informal care for someone living with a chronic or life-limiting condition (Bramwell et al., 1995; Berger et al., 2005; Aslan et al., 2009). Sleep disturbances encompass both an actual and/or perceived difficulty with sleep, resulting in impairment for the caregiver (Berger et al., 2005; Creese et al., 2008; Carney et al., 2011; Cora et al., 2012). As the needs of a patient change along the disease trajectory, there is often an associated increase in the sleep disturbances experienced by a caregiver. An increased prevalence rate (42-95\%) of sleep disturbances is seen in caregivers of advanced cancer patients compared to the $36-80 \%$ caregivers of patients with earlier stages of cancer (Kotronoulas et al., 2013). Common sleep disturbances experienced by caregivers include difficulty falling asleep and maintaining sleep due to frequent disruptions caused by assisting the patient, and hypervigilance at night due to constant monitoring of the patient, or the caregiver's own worries (McCurry et al., 2007; Harding et al., 2012). Caregivers also express concerns over the consequences of their poor sleep, its impact on the patient's quality of care, their ability to continue work, undertake other everyday demands/chores and maintain their caregiving role (Berger et al., 2005; Stenberg et al., 2010). Caregivers' sleep disturbances often persist after the patient's hospitalization or death and can prevent them from resuming their pre-caring commitments (Carter, 2005; Carter et al., 2009). Prolonged poor sleep patterns and habits can also lead to chronic insomnia, create ongoing health issues, and may potentially prolong grief (Carter, 2005; Carter et al., 2009, Monk et al., 2010).

\section{Sleep in Non-Advanced Cancer Groups}

The evidence from studies on non-cancer caregivers suggests that just over a quarter (27\%) of caregivers of patients with Parkinson's disease (Happe \& Berger, 2002) and two-thirds of caregivers of patients with dementia report sleep disturbances (McCurry et al., 2006; Castro et al., 2009; McCurry et al., 2009). The Pittsburgh Sleep Quality Index (PSQI), a self-rated sleep quality questionnaire has been the most commonly used tool in assessing sleep, with global scores of 5 or more indicating moderate to severe sleep disturbances (Buysse et al., 1989). PSQI global scores among younger (,71 years) caregivers of patients with mild to moderate Alzheimer's disease had a global average score of 4.4 (mild sleep disturbance), whereas caregivers of patients with moderatetoseverecases of dementiahadanaverage score of 9.1 (moderate to severe sleep disturbance) (McKibbin etal., 2005). Interestingly, for those caregivers over the age of 71, global scores dropped to 2.2 (no sleep disturbances) in those caring for patients with moderate to severe dementia symptoms and remained the same at 4.4 in caregivers of patients with mild to moderate dementia symptoms. There were two PSQI subscales where older dementia caregivers indicated fewer issues in their perceived sleep quality and sleep latency scales. Just over half (54\%) of primary caregivers of patients with secondary progressive multiple sclerosis had PSQI scores indicating poor sleep, with a global PSQI rating of 6 (Argyriou et al., 2011).

Recent research has suggested a strong correlation between disrupted and/or restricted sleep and increased morbidity (Ferrie et al., 2007; Cappuccio et al., 2010a) and all-cause mortality (Kojima et al., 2000; Kripke et 
al., 2002; Heslop et al., 2002; Youngstedt \& Kripke, 2004; Ferrie et al., 2007; Cappuccio et al., 2010b). Studies investigating the consequences for caregivers experiencing some form of sleep disturbance identified an increased risk of clinical depression (Kochar et al., 2007; Rittman et al., 2009); anxiety (Happe \& Berger, 2002; McCurry et al., 2007; Creese et al., 2008; Chiu et al., 2014); cardiovascular disease (von Känel et al., 2006); caregiver burden (Pollak \& Perlick, 1991, Happe \& Berger, 2002); immune dysfunction (Spiegel et al., 1999); memory impairment (McEwen, 2006; Alhola \& Polo-Kantola, 2007); increased risk of accidents (Grandner et al., 2010); and other cognitive issues (Harrison \& Horne, 2000; McEwen, 2006; Ratcliff \& van Dongen, 2009). Caregivers who experienced disturbed sleep also underwent various physiological changes. Dementia caregivers suffering from sleep disturbances were found to have increased levels of C-reactive protein (CRP) and plasma pro-inflammatory cytokine interleukin-6 (IL-6) (von Känel et al., 2010). Levels of CRP are markers of sleep quality (Fonareva et al., 2011), with increased levels of CRP seen in people suffering chronic insomnia or during periods of sleep deprivation (Parthasarathy et al., 2014). Increased levels of CRP and IL-6 lead to an increased risk of atherosclerosis and heart disease (Bermudez et al., 2002).

\section{Common Subjective and Objective Sleep Measures}

The most commonly used subjective (participant-reported outcomes) and objective sleep measures in- clude the PSQI, the Epworth Sleepiness Scale, and actigraphy.

\section{Subjective Measures}

The PSQI consists of 19 self-rated questions that assess several sleep-related variables over the previous month's sleep, using Likert-type and open-ended responses (Buysse et al., 1989). These questions com- bine into seven subscales (i.e., sleep latency, sleep quality, sleep medication, daytime dysfunction, sleep disturbances, sleep duration, and habitual sleep efficiency), which have a range of 0 to 3 points, with 0 reflecting no sleep disturbances and 3 indicating severe disturbances on the related subscale. These scores combine for an overall global score ranging from 0 to 21 , with global scores equal to or greater than 5 demonstrating severe sleep difficulties on two or more subscales or moderate sleep difficulty on more than three subscales. The PSQI has a diagnostic sensitivity of $89.6 \%$ and specificity of $86.5 \%$ when distinguishing good and poor sleepers (Buysse et al., 1989). The PSQI has been validated in caregivers of oncol- ogy patients, with a Cronbach's a of 0.68 (Carney et al., 2011), 0.69 in 90 female caregivers of dementia patients (Wilcox \& King, 1999), and between 0.83 and 0.89 in healthy and chronically ill individuals (Buysse et al., 1989).

The Epworth Sleepiness Scale (ESS) is a self-ad- ministered tool with a 4-point Likert-type scale that measures the chances of falling asleep in eight every- day situations (Johns, 1991). Scores per question range from 0 (no chance of falling asleep) to 3 (high chance of falling asleep). The overall score, out of 24 , indicates the level of daytime sleepiness, with a score of 10 or more indicating excessive daytime sleepiness (Johns, 1992). The ESS has shown adequate reliability and validity, with a Cronbach's $a$ of 0.77 for female caregivers (Castro et al., 2009) and 0.73 in older adult dementia caregivers (Rowe et al., 2008). 


\section{Objective Measures}

Actigraphy is a valid and reliable sleep/wake mea- sure and is frequently utilized to objectively measure caregivers' rest and activity for prolonged periods and to compare against self-reported sleep measures of sleep onset latency (period of time it takes to fall asleep), total sleep time, sleep efficiency (percentage of time spent asleep) and periods of disturbed sleep against established normative values (Ferrie et al., 2007; Cappuccio et al., 2010a; 2010b). This sensitive and non-invasive measure of activity is captured by placing an accelerometer on a participant's wrist. Ac tigraphy facilitates the identification of sleep and wake periods through differing levels of activity (Lichstein et al., 2006). Actigraphy is a valid and re- liable measure of sleep in a variety of populations (Wilson et al., 1998; Berger et al., 2003). Compared to the gold standard of polysomnographic recordings, actigraphy exhibits a $90 \%$ agreement (de Souza et al., 2003)

\section{Rationale}

Given the risks to caregivers' health and well-being, a better understanding of the sleep patterns of care- givers of patients with advanced cancer is required to identify any gaps in the literature and inform further research in order to help improve caregivers' sleep patterns.

\section{Aim}

The aim of the present systematic review was to com- pare and examine all of the empirical literature re- porting on the sleep of the caregivers of patients with advanced cancer in order to determine the sleep patterns of caregivers of patients with advanced cancer.

\section{METHODS}

This systematic review set out to determine the sleep patterns of caregivers of patients with advanced cancer. The review adheres to the Preferred Reporting Items for Systematic Reviews and Meta-Analysis (PRISMA) Statement. An electronic database search was conducted on the following databases: MED- LINE (19482015), CINAHL (1982-2015), Embase (1980-2015), PubMed (1960-2015), PsycINFO(1806-2015), AMED (1985-2015), Scopus (1823-2015), and the Cochrane Library(1991-2015). Thefinal database search was conducted on May 23, 2015. No date restrictions were imposed on the database searches, which ensured that all relevant studies were identified The following search terms were used: "sleep," "insomnia," "sleep disturbance," "circadian rhythm," "caregiver," "carer," "advanced cancer," and "palliative cancer," including suggested MESH terms from the databases (see Table 1). The inclusion criteria required studies to be published in an English peerre- viewed journal and to have reported empirical objective and/or subjective sleep data from informal adult caregivers of patients with advanced cancer. The relevant reference lists of selected studies that met the inclusion criteria were hand-searched to allow for a more comprehensive search. Unpublished studies, conference papers, and dissertations were excluded from our systematic review.

Two reviewers (KM and CS) screened the studies in a blinded fashion, checking the retrieved studies against the inclusion criteria. In the case of discrepancies, a third arbitrator (EL) helped the group reach a consensus 
Table 1: Electronic Databases search and search terms used

Electronic Databases search

Medline (1948 - 2015)

CINAHL (1982 - 2015)

Embase (1980 - 2015)

PubMed (1960 - 2015)

PsycINFO (1806 - 2015)

AMED (1985 - 2015)

Scopus (1823 - 2015)

The Cochrane Library $(1991-2015)$

Search terms

1. (sleep OR insomnia OR "sleep disturbance" OR "circadian rhythm") AND (caregiver OR carer) AND ("advanced cancer" OR "palliative cancer")

\section{Data Extraction}

Available participant information, subjective and objective sleep measures, and questionnaire scores were extracted (KM), including age, gender, relationship to the patient, whether they resided with the patient, employment, duration of caregiving, and the amount of time per day spent caregiving. The sleep data extracted included subjective and objective total sleep time, sleep onset latency, and sleep efficiency.

\section{Quality Assessment}

A systematic appraisal of the methodological quality of the included studies was conducted using a validated scoring system developed by Hawker et al. (2002) (see Table 2). This methodological quality system was used due to the heterogeneous data and the variety of methodologies among the studies (Appendix A). This nine-item critical appraisal tool allows a score between 1 ("very poor") and 4 ("good"), with explicit detail of the requirements for each score to be assigned to each study: abstract and title, introduction and aims, methods and data, sampling, data analysis, ethics and bias, results, transferability/generalizability, and implications. The final result, out of 36 (maximum), is calculated by totalling each section, with higher scores reflecting higher study quality.

\section{ANALYSIS}


Weighted means and standard deviations were utilized to calculate the age of the caregiver and patient, the months and hours spent caregiving, PSQI values, subjective sleep times (total sleep time, sleep onset latency, and sleep efficiency), and actigraphy values (total night sleep time, sleep onset latency, sleep efficiency, wake after sleep onset and nap times). Overall percentages were calculated for data on spouses, gen- der, employment, and sleep efficiency. Calculation of an overall mean was carried out on studies that presented more than one dataset in the above measures (i.e., several days worth of data) before the calculation of weighted averages was conducted (Carter, 2003; Gibbins et al., 2009). In the intervention study, the baseline measures for both the intervention and control datasets were averaged to create an overall average for that study (Carter, 2006).

Thematic content analysis (KM and JP) of the pub- lished qualitative quotes allowed for the generation of major themes (Carter, 2002; Hearson et al., 2011). Each quote was read and categorized into the causes or consequences of poor sleep until major themes emerged in each section and a consensus was reached. In addition, examples of caregiver narratives from each major theme were provided from the identified papers.

\section{RESULTS}

An initial search identified 330 studies, which was reduced to 287 studies once duplicates were eliminated. A review of titles and abstracts identified 256 studies that did not meet the inclusion criteria and were excluded, leaving 31. A further seven stud- ies were excluded as full-text versions were unavailable-manuscript requests were sent to the library at The University of Notre Dame Australia, which was unable to obtain the required studies at that time, leaving 24 studies, which were examined in detail. A further 16 studies were excluded after an investigation of the full text identified that they did not meet the inclusion criteria, leaving 8 studies. The bibliographies of these 8 studies were hand-searched for titles that met the inclusion criteria. Abstracts and full text were then obtained and analyzed, resulting in the inclusion of 3 additional studies that met the inclusion criteria, for a total of 11 studies.

A final review of these 11 studies identified three manuscripts (Carter \& Chang, 2000; Carter, 2002; Carter \& Acton, 2006) that reported on the same dataset. Confirmation from the author was sought, as well as identification of the primary study. The sleep data reported in the primary study (Carter \& Chang, 2000) were used in this systematic review, and the secondary paper provided additional analysis of the primary data, which was included separately in the results and qualitative narratives of caregivers' sleep (Carter, 2002). The final manuscript was excluded as no further caregiver sleep data were provided (Carter \& Acton, 2006), At the end of this process, 10 studies were included in our systematic review (see Figure 1).

\section{Study Design and Methodological Quality}

A majority of the studies were cross-sectional in design ( $\left.n^{1 / 4} 7\right)$ (Carter \& Chang, 2000; Flaskerud et al., 2000; Carter, 2002; 2003; Hearson et al., 2011; Delgado- Guay et al., 2013; Lee et al., 2015), with the remainder including prospective studies $\left(n \frac{1}{4} 2\right.$ ) (Gibbins et al., 2009; Lee et al., 2014) and one repeated-measures experimental 
design interventional study (Carter, 2006). The quality assessment scores ranged between 25 and 36 (fair to good), with a mean of $32(+3.09)$, demonstrating good overall methodological quality (Hawker et al., 2002). Due to the limited number of studies, none were excluded based on methodological quality.

\section{Table 2}

Figure 1

\section{Characteristics of the Sample}

The included studies involved 596 caregivers based in five Northern Hemisphere countries classified as middle or high-income (see Table 2). Study sample sizes ranged widely from 10 to 176 . The weighted average age of caregivers in the eight studies reporting a mean age was $47.9(+3.51)$ years (Carter \& Chang, 2000; Flaskerud et al., 2000; Carter, 2002; 2003;

2006; Hearson et al., 2011; Lee et al., 2014; 2015), while a higher median age was reported in two studies (66 and 52 years) (Gibbins et al., 2009; Delgado- Guay et al., 2013). The majority of caregivers (75\%) were females (Flaskerud et al., 2000; Carter, 2003; 2006; Gibbins et al., 2009; Hearson et al., 2011; Delgado-Guay et al., 2013; Lee et al., 2014; 2015); spouses (57\%) (Flaskerud et al., 2000; Carter, 2003; 2006; Hearson et al., 2011; Delgado-Guay et al., 2013; Lee et al., 2014; 2015); caring for a male patient (60\%) (Carter, 2003; Hearson et al., 2011; Lee et al., 2014; 2015) who was aged $60.2(+3.2)$ years (Carter, 2003; Hearson et al., 2011; Lee et al., 2014; 2015) with advanced cancer.

These caregivers had been providing care for $22.45(+5.55)$ months (Carter \& Chang, 2000; Flaskerud et al., 2000; Carter, 2003) and spent more than half of each day $(X 1 / 416.08$ hours/day, +1.29$)$ on caregiving duties (Carter \& Chang, 2000; Flaskerud et al., 2000; Carter, 2003; 2006). In three studies, 23-53\% of care- givers were also in paid employment (Hearson et al., 2011; Delgado-Guay et al., 2013; Lee et al., 2014), and 16\% also had primary homemaker responsibilities (Delgado-Guay et al., 2013). More than a third $(38.5 \%)$ of caregivers had to adapt their work schedule to cope with the demands of caregiving (Hearson et al., 2011). Some caregivers had to reduce their work hours $(59 \%)$ or leave work $(15 \%)$ as a result of taking on the role of unpaid caregiving (Carter, 2002).

Two studies excluded participants with known major sleep disorders (sleep apnea, periodic limb movement disorders) (Carter, 2003; 2006). Three studies noted that more than a third $(36 \%)$ of caregivers experienced premorbid sleep disorders but did not specify the type of sleep disorders experienced (Gibbins et al., 2009; Lee et al., 2014; 2015). Only one study investigated sleeping arrangements and found that $90 \%\left(n \frac{1}{4} 9\right)$ of caregivers still slept in the same bed as their spouse (Carter, 2003).

\section{Objective Sleep Results}

Some 6 of the 10 studies used actigraphy as an objective measure of caregivers' sleep. The length of 
actigraphy data collection ranged from 48 (Lee et al., 2014; 2015) to 72 hours (Carter, 2003; 2006; Hearson et al., 2011) and up to several days (Gibbins et al., 2009). The average total nightly sleep was 270.14 minutes (4.5 hours) (+ 53.76) (Carter, 2003; 2006; Hearson et al., 2011; Lee et al., 2014; 2015), which is a 43.7\% reduction from the recommended 8 hours. Mean sleep onset latency was 11.35 minutes (+5.06) (Carter, 2003; 2006; Lee et al., 2014; 2015). However, one study (Carter, 2003) reported a markedly increased sleep onset latency ranging from 40 to 45 minutes over a 10-week period. The percentage of time spent sleeping (sleep efficiency) ranged from 73 to $92 \%$ and had an average of $84.27 \%$ across five studies (Carter, 2003; 2006; Gibbins et al., 2009; Lee et al., 2014; 2015). Two-thirds of caregivers $\left(n^{1 / 4} 9\right)$ in one study (Hearson et al., 2011) met a higher sleep efficiency threshold of $85 \%$. Caregivers on average spent 38.57 minutes (+0.91) awake after sleep onset (Carter, 2006; Hearson et al., 2011; Lee et al., 2014) and 96.58 minutes (+4.94) napping during the day (Lee et al., 2014; 2015).

\section{Subjective Sleep Results}

The PSQI (Buysse et al., 1989) was the most frequently used subjective assessment scale $\left(n^{1 / 1} 48\right)$ (Carter \& Chang, 2000; Flaskerud et al., 2000; Carter, 2002; 2003; 2006; Delgado-Guay et al., 2013; Lee et al., 2014; 2015). The ESS was employed in two studies (Gibbins et al., 2009; Hearson et al., 2011). Two qualitative studies utilized open-ended semi-structured interview questions to obtain care- giver perceptions about their sleep (Carter, 2002; Hearson et al., 2011).

Across studies, the mean global PSQI score was 9.04 (+0.92) (Carter \& Chang, 2000; Carter, 2006; Hearson et al., 2011; Delgado-Guay et al., 2013; Lee et al., 2014; 2015). In these studies, $72.2-100 \%$ of caregivers had a moderate to severe level of sleep disturbance (PSQI global scores 2'5) (Carter, 2003; 2006; Hearson et al., 2011; Delgado-Guay et al., 2013; Lee et al., 2014; 2015). The PSQI subscales (0 1/4 no difficulty, $3 \frac{1}{4}$ severe difficulty) revealed that caregivers had moderate difficulties in the following sleep domains: quality $\left(X^{1 / 4} 1.60+0.04\right)$, duration $\left(X^{1 / 1 / 4} 1.63+0.37\right)$, daytime dysfunction $\left(X^{1 / 4} 1.61+0.08\right)$, sleeponset latency $\left(X^{1 / 4} 1.5+0.02\right)$, efficiency $\left(X^{1} / 41.43+0.05\right)$, and disturbances $\left(X^{1 / 4} 1.19+0.45\right)($ Carter \& Chang, 2000; Lee et al., 2014; 2015). Sleep medication usage subscale scores were consistently low in all studies $(0.42+0.16)$ (Carter \& Chang, 2000; Lee et al., 2014; 2015).

A secondary study did further sub-analysis (Carter, 2002) from previously published PSQI values collected during a primary study (Carter \& Chang,2000). This analysis found that, while men claimed to have better sleep quality $(X 1 / 411.0+3.71)$ com- pared to women $\left(X^{1 / 4} 11.53+4.56\right)$, there was no statistical difference between genders (Carter, 2002). There was also no statistical difference be- tween the sleep quality of spousal $(X 1 / 411.39+4.25)$ and non-spousal $\left(X^{1} 1 / 411.50+4.76\right)$ caregivers (Carter, 2002).

Caregivers' subjective total sleep time was calculated at 355.83 minutes (+8.48; 5.93 hours) (Carter, 2003; 2006; Lee et al., 2015). Sleep onset latency was on average 27.45 minutes (+1.67) (Carter, 2006; 2003). Sleep efficiency was reported to be $78 \%$ (Carter, 2003; 2006). Studies using the ESS found that 15 to $38.5 \%$ of caregivers experienced daytime sleepiness, with an elevated score of 2'11 (Gibbins et al., 2009; Hearson et al., 2011). 


\section{Caregiver Narratives}

The five themes generated by the thematic content analysis of the two included qualitative studies (Carter, 2002; Hearson et al., 2011) were patient-related factors, hypervigilance, depression, fatigue, and quality of life. These themes revealed caregivers' perceptions of the causative factors and the impact of their sleep disturbances.

Caregivers described how patient-related disturbances directly impacted their own sleep:

Four minutes and then a cough again, and so he literally just never slept, and neither did I. (Carter, 2002, p. 1280)

The patient's health at the time also influenced sleeping arrangements:

So I have to judge how she is before I go to bed, whether I can go to sleep without worrying you know, sleep in my bed, or is it a couch night? If I sleep on the couch, I hardly get any sleep. (Hearson et al., 2011, p. 73)

Caregivers felt that sleep disturbances directly impacted their ability to perform day-to-day activities for themselves and for the patient:

If I sleep on the couch, I hardly get any sleep, and that's when I was closing my eyes [while driving] on my way home from work, or even on the way to work. l'd come to a stop sign and my eyes would be closing. So that was scary. (Hearson et al., 2011, p. 74)

Despite caregivers acknowledging the myriad consequences of their disturbed sleep, they also minimized the significance of their accumulating sleep deficit, believing they could manage with less sleep, or perhaps catch up later on (Hearson et al., 2011):

I sort of sacrifice myself at this point. I'm not as important here. Right now, I feel I have enough sleep. Even if I don't sleep soundly, at least I'm reclining and resting. I cheer myself on ... as long as I get one good night's sleep a week, or maybe I'll be able to make up for it in the next week or so. (Hear- son et al., 2011, p. 73)

Caregivers noted the impact that their sleep patterns had on their mood:

I notice in myself if I don't get enough rest, then I am more stressed, and I get more depressed. (Carter, 2002, p. 1280) 
Feelings ranged from sadness, depression, to stress, and even anger toward the patient due to disrupted sleep:

Sleep deprivation is something. Yesterday and the day before were the first two days that I felt angry with her for getting me up ... I felt so sad after- wards. She can't help her disease. (Carter, 2002, p. 1280)

\section{DISCUSSION}

Our systematic review identified 10 studies that provided empirical data concerning the sleep of in- formal caregivers of advanced cancer patients. The main outcome found in all of these studies was that a high percentage of caregivers experienced sleep disturbances, with large reductions seen in total sleep time. While there were no major differences between objective and subjective sleep values, caregivers tended to overestimate the total amount of sleep they achieved each night. Caregivers' perceptions about their sleep onset differed be tween studies. This difference in sleep perception may come down to caregivers feeling like they are awake despite being in the lighter stages of sleep. Sleep efficiency was the one area where caregivers' subjective assessments were similar to the objective measures.

The subjective sleep quality seen in PSQI scores highlighted that most caregivers experienced moderate to severe sleep disturbances with issues in the subsections related to total sleep time, quality of sleep, and daytime dysfunction. The objective measurement of sleep through actigraphy was able to support these difficulties with reductions in total sleep time seen in all studies and variations of sleep onset. Interestingly, despite the reported daytime dysfunction, caregivers did not report a high level of daytime sleepiness on the Epworth Sleepiness Scale. This discrepancy may come down to the focus of the questions between the two different tests. As the ESS questions focus on specific scenarios, like falling asleep while driving, some participants may assign a score of zero to scenarios in which they didn't participate. This can result in scores that do not reflect a participant's true level of sleepiness. Furthermore, the ESS questions reflect the participant's degree of fatigue in several scenarios at the moment, compared to the PSQI, where there are only two questions used to investigate daytime dysfunction over the previous month. Caregivers' narratives supported the results from the PSQI over the ESS, showing that they did feel that their sleep disturbances had a negative impact on their ability to function during the day. When considering either the PSQI or ESS as a tool for measuring care- givers' fatigue, the PSQI seems to yield a more consistent outcome validated by caregivers' own descriptions.

Another subsection of interest on the PSQI was sleep medication usage. Caregivers consistently had low scores, indicating that few caregivers used sleeping tablets to assist with their sleep difficulties. Caregivers' narratives gave insight into this in that they tended to avoid sleep medications due to their sedative effects and the impact these could have on their ability to respond to the needs of the patient during the night (Carter, 2002).

Of the sleep disturbances observed in caregivers, total sleep time fell considerably below the recommended healthy sleep time of 7 to 9 hours, with older adults needing around 7 hours of sleep (National Sleep 
Foundation, 2015), and with caregivers getting on average only 270.14 minutes per night ( 4.5 hours;

+53.76) (Carter, 2003; 2006; Hearson et al., 2011; Lee et al., 2014; 2015). This large reduction in sleep time could have a negative consequence on caregivers' health and well-being (Banks \& Dinges, 2007). Caregivers did acknowledge this reduction in sleep time, but most believed that they could deal with it or catch up later.

When investigating areas of sleep that might cause a reduction in total sleep time, sleep onset in all but one study fell within normal limits (10-20 minutes) (Ohayon et al., 2004). The sleep onset in one study (Carter, 2003) was up to double the time in both objective and subjective measures. When comparing the participant information and study methods, there was no obvious reason for this discrepancy. This shows that they did not have difficulty falling asleep when the caregiver did go to bed for sleep.

Finally, caregivers' sleep efficiency fell mostly within the normative range of $80-85 \%$ (Ohayon et al., 2004) when measured objectively. However, it should be noted that sleep efficiency was calculated differently between studies, with some including any daytime sleep (Carter, 2003). When sleep efficiency during the night was calculated, caregivers fared quite well. It was only when caregivers' sleep efficiency was calculated for all sleep periods over 24 hours (i.e., naps) that it dropped below normal (Lee et al., 2014). One study measured both subjective and objective sleep efficiency, with caregivers slightly underestimating their sleep efficiency (Carter, 2003). However, it can be seen that during the night most caregivers did not experience any significant sleep disturbances according to these measures and that this doesn't account for the reduction in total sleep time.

Caregiver narratives offered some interesting insights showing that caregivers acknowledge that they suffer from sleep issues and the consequences for themselves and the patient. However, the perceptions gleaned from the narrative examples given and overview from the authors show that caregivers see sleep disturbances as something that they just have to accept, and that they will catch up on their sleep deficit later on. However, they do not seem to believe that this period of poor sleep will have long-term health consequences. There is also no research on these caregivers in the future to examine if their sleep has reverted to pre-caregiving levels. Learned sleep habits may continue even in the absence of the patient-related factors that caused the hypervigilance, which requires intervention to assist in improving quality of sleep.

Compared to other caregiving groups, caregivers of advanced cancer patients had a similar or higher level of subjective sleep disturbances. With a global PSQI of 9.04, caregivers of patients who have advanced cancer expressed a similar level of sleep disturbances as caregivers of patients with moderate to severe Alzheimer's disease (PSQI 1/4 9.1; McKibbin et al., 2095). However, the proportion of caregivers experiencing some level of sleep disturbances was much higher in this group, with studies ranging from 72 to $100 \%$ of participants reporting moderate to severe sleep disturbances compared to only a third of caregivers of Parkinson's disease patients (Happe

\& Berger, 2002), half of multiple sclerosis caregivers (Argyriou et al., 2011), and two-thirds of dementia caregivers (McCurry et al., 2007; 2009). There is no current research that compares these groups and the reasons behind these differing levels. The age of caregivers could have an effect on the level of sleep disturbances. The weighted average age of the care- givers in this systematic review was $47.9(+3.51)$ years (Carter \& Chang, 2000; Flaskerud et al., 2000; Carter, 2002; 2003; 2006; Hearson et al., 
2011; Lee et al., 2014; 2015), with up to half (23-53\%) still employed in other roles (Hearson et al., 2011; Delgado-Guay et al., 2013; Lee et al., 2014). This middle-aged working group of caregivers may account for the increased level of sleep disturbances compared to older adults who are retired and can have more flexibility in their sleep schedule, and sleep disturbances may have less of an impact on their daily routine. Caregivers of patients with Parkinson's and Alzheimer's disease were significantly older, with mean ages of 62.3 (Happe \& Berger, 2002) and 71.1 (McKibbin et al., 2005), respectively. Further research is required to understand whether the main causes of sleep disorders are the differing age groups of caregivers, differences in caregiving duties required, or specific patient symptoms.

While this systematic review did not investigate the effect of sleep disturbance on mood, some studies highlighted a connection between caregivers' poor sleep and levels of depression (Carter \& Chang, 2000; Carter, 2002; Lee et al., 2014). Caregivers in descriptions of their sleep described mood disturbances such as depression, anxiety, and anger as a result of poor sleep. Caregivers did acknowledge that they were having issues due to their poor sleep, with the resulting negative effects on their mood and well-being (Hearson et al., 2011).

\section{LIMITATIONS OF THE STUDY}

This review has a number of limitations due to the limited number of articles available. Several articles identified in the electronic search were inaccessible, and there is the possibility of relevant data being missed. Some studies did not clearly state whether patients with advanced cancer were included; we thus may have inadvertently omitted studies that were reporting on the target population. The different actigraphy data collection sampling rates and reporting information limited our ability to compare data. Due to the heterogeneous nature of the outcome measures used and the reporting of the study results, it was difficult to completely compare and contrast the data presented in these studies.

\section{CONCLUSIONS}

For caregivers looking after patients with advanced cancer, a majority suffered from moderate to severe sleep disturbances with a substantial reduction in total sleep time. While caregivers acknowledge the negative impact of sleep disturbances on their mood, the decrease in total sleep time puts caregivers at risk for developing medical issues and can have a

negative impact on their mood. A logical step for future research would be a longitudinal assessment of caregivers' sleep to investigate the changes that might occur over the entire cancer trajectory and specific changes during the end of life. A better under- standing of the development and continuation of sleep disturbances and which factors have the big- gest impact could be helpful in predicting potential negative changes in sleep patterns that might be preventable. The development of screening tools could also assist clinicians in ascertaining if and when assistance may need to be provided to improve caregivers' sleep. Finally, and most importantly, interventions need to be created that take into consideration the limitations that the caregiving role may have in terms of preventing them from attending more traditional therapy programs that run for several weeks. 


\section{ACKNOWLEDGMENTS}

We would like to thank the librarians at The University of Notre Dame Australia for their assistance in retrieving electronic journals.

\section{CONFLICTS OF INTEREST}

The authors hereby declare that there are no financial or personal conflicts of interest in the present study or in the development of this submission.

\section{FUNDING}

This review was supported through the Australian Government's Collaborative Research Networks pro- gram.

\section{REFERENCES}

Alhola, P. \& Polo-Kantola, P. (2007). Sleep deprivation: Impact on cognitive performance. Neuropsychiatric Disease and Treatment, 3(5), 553-567. Available from https:// www.ncbi.nlm.nih.gov/pmc/articles/PMC2656292/pdf/ NDT3-553.pdf.

Argyriou, A.A., Karanasios, P., Assimakopoulos, K., et al. (2011). Assessing the quality of sleep in Greek primary caregivers of patients with secondary progressive multi- ple sclerosis: A cross-sectional study. Journal of Pain and Symptom Management, 42(4), 541-547. Epub ahead of print Mar 27. Available from http://www. jpsmjournal.com/article/S0885-3924(11)00074-1/pdf.

Aslan, O., Sanisoglu, Y., Akyol, M., et al. (2009). Quality of sleep in Turkish family caregivers of cancer patients. Cancer Nursing, 32(5), 370-377.

Banks, S. \& Dinges, D.F. (2007). Behavioral and physiolog- ical consequences of sleep restriction. Journal of Clinical Sleep Medicine, 3(5), 519-528. Available from https:/www.ncbi.nlm.nih.gov/pmc/articles/ PMC1978335/pdf/jcsm.3.5.519.pdf.

Berger, A.M., VonEssen, S., Kuhn, B.R., et al. (2003). Adherence, sleep, and fatigue outcomes after adjuvant breast cancer chemotherapy: Results of a feasibility intervention study. Oncology Nursing Forum, 30(3), $513-522$.

Berger, A.M., Parker, K.P., Young-McCaughan, S., et al. (2005). Sleep-wake disturbances in people with cancer and their caregivers: State of the science. Oncology Nursing Forum, 32(Suppl. 6), E98-E126.

Bermudez, E.A., Rifai, N., Buring, J., et al. (2002). Interrelationships among circulating interleukin-6, C-reactive protein, and traditional cardiovascular risk factors in women. Arteriosclerosis, Thrombosis, and Vascular Bi- ology, 22(10), 1668-1673. Available from http://atvb. ahajournals.org/content/22/10/1668.long.

Bramwell, L., MacKenzie, J., Laschinger, H., et al. (1995). Need for overnight respite for primary caregivers of hospice clients. Cancer Nursing, 18(5), 337-343.

Buysse, D.J., Reynolds, C.F., Monk, T.H., et al. (1989). The Pittsburgh Sleep Quality Index: A new instrument for psychiatric practice and research. Psychiatry Research, 28(2), 193-213. 
Cappuccio, F.P., D’Elia, L., Strazzullo, P., et al. (2010a). Quantity and quality of sleep and incidence of type 2 diabetes: A systematic review and meta-analysis. Diabetes Care, 33(2), 414-420. Available from https://www.ncbi. nlm.nih.gov/pmc/articles/PMC2809295/pdf/zdc414. pdf.

Cappuccio, F.P., D’Elia, L., Strazzullo, P., et al. (2010b). Sleep duration and all-cause mortality: A systematic review and meta-analysis of prospective studies. Sleep, 33(5), 585-392. Available from https://www.ncbi.nlm. nih.gov/pmc/articles/PMC2864873/pdf/aasm.33.5.585.pdf.

Carney, S., Koetters, T., Cho, M., et al. (2011). Differences in sleep disturbance parameters between oncology out- patients and their family caregivers. Journal of Clinical Oncology, 29(8), 1001-1006. Epub ahead of print Jan 31. Available from https://www.ncbi.nlm.nih.gov/pmc/ articles/PMC3068050/pdf/zlj1001.pdf.

Carter, P.A. (2002). Caregivers' descriptions of sleep changes and depressive symptoms. Oncology Nursing Forum, 29(9), 1277-1283.

Carter, P.A. (2003). Family caregivers' sleep loss and de- pression over time. Cancer Nursing, 26(4), 253-259.

Carter, P.A. (2005). Bereaved caregivers' descriptions of sleep: Impact on daily life and the bereavement process. Oncology Nursing Forum, 32(4), 741.

Carter, P.A. (2006). A brief behavioral sleep intervention for family caregivers of persons with cancer. Cancer Nursing, 29(2), 95-103.

Carter, P.A. \& Acton, G. (2006). Personality and coping: Predictors of depression and sleep problems among caregivers of individuals who have cancer. Journal of Gerontological Nursing, 32(2), 45-53.

Carter, P.A. \& Chang, B. (2000). Sleep and depression in cancer caregivers. Cancer Nursing, 23(6), 410-415.

Carter, P.A., Mikan, S.Q. \& Simpson, C. (2009). A feasibil- ity study of a two-session home-based cognitive behavioral therapy-insomnia intervention for bereaved family caregivers. Palliative \& Supportive Care, 7(2), 197-206.

Castro, C.M., Lee, K.A., Bliwise, D.L., et al. (2009). Sleep patterns and sleep-related factors between caregiving and non-caregiving women. Behavioral Sleep Medicine,7(3), 164 - 79.

Chiu, Y.C., Lee, Y.N., Wang, P.C., et al. (2014). Family care givers' sleep disturbance and its associations with multilevel stressors when caring for patients with dementia. Aging \& Mental Health, 18(1), 92-101. Epub ahead of print Sep 20, 2013.

Cora, A.M.S., Partinico, M.M.S., Munafo, M.P., et al. (2012). Health risk factors in caregivers of terminal cancer patients: A pilot study. Cancer Nursing, 35(1), 38-47.

Creese, J., Bédard, M., Brazil, K., et al. (2008). Sleep distur- bances in spousal caregivers of individuals with Alzheimer's disease. International Psychogeriatrics, 20(1), 149-161. Epub ahead of print Apr 30, 2007.

de Souza, L., Benedito-Silva, A.A., Pires, M.L., et al. (2003). Further validation of actigraphy in the study of sleep and circadian rhythms: An update for 2002. Sleep, 26, 81-85.

Delgado-Guay, M., Parsons, H., Hui, D., et al. (2013). Spiri- tuality, religiosity, and spiritual pain among caregivers of patients with advanced cancer. The American Jour- nal of Hospice \& Palliative Care, 30(5), 455-461. Epub ahead of print Sep 4, 2012.

Ferrie, J.E., Shipley, M.J., Cappuccio, F.P., et al. (2007). A prospective study of change in sleep duration: Associations with mortality in the Whitehall II Cohort. Sleep, 30(12), 1659-1666. Available from 
https://www.ncbi. nlm.nih.gov/pmc/articles/PMC2276139/pdf/aasm.30. 12.1659.pdf.

Flaskerud, J.H., Carter, P.A. \& Lee, P. (2000). Distressing emotions in female caregivers of people with AIDS, age-related dementias, and advanced-stage cancers. Perspectives in Psychiatric Care, 36(4), 121-130.

Fonareva, I., Amen, A.M., Zajdel, D.P., et al. (2011). Assessing sleep architecture in dementia caregivers at home using an ambulatory polysomnographic system. Journal of Geriatric Psychiatry and Neurology, 24(1), 50-59. Available from https:/www.ncbi.nlm.nih.gov/ pmc/articles/PMC3342770/pdf/nihms371227.pdf,

Gibbins, J., McCoubrie, R., Kendrick, A.H., et al. (2009). Sleep-wake disturbances in patients with advanced cancer and their family carers. Journal of Pain and Symptom Management, 38(6), 860-870. Available from http://www.jpsmjournal.com/article/S0885-3924 (09)00709-X/pdf.

Grandner, M.A., Patel, N.P., Gehrman, P.R., et al. (2010). Problems associated with short sleep: Bridging the gap between laboratory and epidemiological studies. Sleep Medicine Reviews, 14(4), 239-247. Epub ahead of print Nov 6, 2009. Available from https://www.ncbi.nlm.nih.gov/pmc/articles/PMC2888649/pdf/nihms144089.pdf.

Happe, S. \& Berger, K. (2002). The association between caregiver burden and sleep disturbances in partners of patients with Parkinson's disease. Age and Ageing, 31(5), 349-354. Available from http://ageing.oxford- journals.org/content/31/5/349.long.

Harding, R., Epiphaniou, E., Hamilton, D., et al. (2012). What are the perceived needs and challenges of informal caregivers in home cancer palliative care? Qualitative data to construct a feasible psycho-educational intervention. Supportive Care in Cancer, 20(9), 1975-1982. Epub ahead of print Nov 10, 2011.

Harrison, Y.\& Horne, J.A. (2000). The impact of sleep deprivation on decision making: A review. Journal of Experimental Psychology. Applied, 6(3), 236-249. Available from http://postcog.ucd.ie/files/Hrrison\%20and\%20horne.pdf.

Hawker, S., Payne, S., Kerr, C., et al. (2002). Appraising the evidence: Reviewing disparate data systematically. Qualitative Health Research, 12(9), 1284-1299.

Hearson, B., McClement, S., McMillan, D.E., et al. (2011). Sleeping with one eye open: The sleep experience of family members providing palliative care at home. Journal of Palliative Care, 27(2), 69-78.

Heslop, P., Smith, G.D., Metcalfe, C., et al. (2002). Sleep duration and mortality: The effect of short or long sleep duration on cardiovascular and all-cause mortality in working men and women. SleepMedicine, 3(4), 305314.

Johns, M.W. (1991). A new method for measuring daytime sleepiness: The Epworth Sleepiness Scale. Sleep, 14(6), 540-545. Available from http://epworthsleepinesss-scale.com/wpcontent/uploads/2016/06/a_new_method_for_measure_daytime_sleepiness_the_epworth_sleepiness_scale1.pdf,

Johns, M.W. (1992). Reliability and factor analysis of the Epworth Sleepiness Scale. Sleep, 15(4), 376-381. Available from http://www.mwjohns.com/wp-content/ uploads/2009/murray_papers/reliabiltiy_and_factor_ analysis_of_the_epworth_sleepiness_scale.pdf.

Kochar, J., Fredman, L., Stone, K.L., et al. (2007). Sleep problems in elderly women caregivers depend on the level of depressive symptoms: Results of the Care-giver Study of Osteoporotic Fractures. Journal of the 
American Geriatrics Society, 55(12), 2003-2009. Epub ahead of print Oct 18.

Kojima, M., Wakai, K., Kawamura, T., et al. (2000). Sleep patterns and total mortality: A 12-year follow-up study in Japan. Journal of Epidemiology, 10(2), 87-93. Avail able from https://www.jstage.jst.go.jp/article/jea1991/ 10/2/10_2_87/_pdf.

Kotronoulas, G., Wengstrom, Y. \& Kearney, N. (2013). Sleep patterns and sleep-impairing factors of persons providing informal care for people with cancer: A critical review of the literature. Cancer Nursing, 36(1), E1E15.

Kripke, D.F., Garfinkel, L., Wingard, D.L., et al. (2002). Mortality associated with sleep duration and insomnia.Archives of General Psychiatry, 59(2), 131-136.

Lee, K., Yiin, J., Lu, S., et al. (2014). The burden of caregiving and sleep disturbance among family caregivers of advanced cancer patients. CancerNursing, 38(4), E10-E19.

Lee, K., Yiin, J., Lin, P., et al. (2015). Sleep disturbances and related factors among family caregivers of patients with advanced cancer.Psycho-Oncology, 24(12),1632-1638. Epub ahead of print Apr 14.

Lichstein, K.L., Stone, K.C., Donaldson, J., et al. (2006). Actigraphy validation with insomnia. Sleep, 29(2), 232 -239. Available from http:/www.journalsleep.org/ Articles/290214.pdf.

McCurry, S.M., Vitiello, M.V., Gibbons, L.E., et al. (2006). Factors associated with caregiver reports of sleep disturbances in persons with dementia. The American Journal of Geriatric Psychiatry, 14(2), 112-120.

Available from http:/faculty.washington.edu/vitiello/Recent\%20

Publications/065\%20\%20Factors\%20associated\%20with\% 20caregiver\%20reports.pdf.pdf.

McCurry, S.M., Logsdon, R.G., Teri, L., et al. (2007). Sleep disturbances in caregivers of persons with dementia: Contributing factors and treatment implications. Sleep Medicine Reviews, 11(2), 143-153. Epub ahead of print Feb 6. Available from https:/www.ncbi.nlm.nih.gov/pmc/articles/PMC1861844/pdf/nihms20118.pdf.

McCurry, S.M., Gibbons, L.E., Logsdon, R.G., et al. (2009). Insomnia in caregivers of persons with dementia: Who is at risk and what can be done about it? Sleep Medicine Clinics, 4(4), 519-526. Available from https:/www. ncbi.nlm.nih.gov/pmc/articles/PMC2799891/pdf/ nihms-116341.pdf.

McEwen, B.S. (2006). Sleep deprivation as a neurobiologic and physiologic stressor: Allostasis and allostatic load. Metabolism, 55(10 Suppl. 2), S20-S23.

McKibbin, C.L., Ancoli-Israel, S., Dimsdale, J., et al. (2005). Sleep in spousal caregivers of people with Alzheimer's disease. Sleep, 28(10), 1245-1250. Available from http://www.journalsleep.org/Articles/281012.pdf.

Monk, T.H., Germain, A. \& Reynolds, C.F. (2010). Sleep dis- turbances in bereavement. Psychiatric Annals, 38(10), 671-675. Available from https://www.ncbi.nlm.nih. gov/pmc/articles/PMC2826218/pdf/nihms166541.pdf.

National Sleep Foundation (2015). National Sleep Foundation recommends new sleep durations. Washington, DC:

National Sleep Foundation. Available from https:// sleepfoundation.org/media-center/press-release/nationalsleep-foundation-recommends-new-sleep-times.

Ohayon, M.M., Carskadon, M.A., Guilleminault, C., et al. (2004). Meta-analysis of quantitative sleep parameters from childhood to old age in healthy individuals: Developing normative sleep values across the human lifespan. Sleep, 27(7), 1255-1273. Available from http://www.ihf- 
global.com/education_documents/REMSleep.pdf.

Parthasarathy, S., Vasquez, M.M., Halonen, M., et al. (2014). Persistent insomnia is associated with mortality risk. The American Journal of Medicine, 128(3), 268-275. Epub ahead of print Oct 16. Available from https:/www.ncbi.nlm.nih.gov/pmc/articles/ PMC4340773/pdf/nihms-635632.pdf,

Pollak, C.P. \& Perlick, D. (1991). Sleep problems and institutionalization of the elderly. Journal of Geriatric Psychiatry and Neurology, 4(4), 204-210.

Ratcliff, R. \& van Dongen, H.P.A. (2009). Sleep deprivation affects multiple distinct cognitive processes. Psychonomic Bulletin \& Review, 16(4), 742-751. Available from https://www.ncbi.nlm.nih.gov/pmc/articles/PMC 2797337/pdf/nihms155296.pdf.

Rittman, M., Hinojosa, M.S. \& Findley, K. (2009). Subjective sleep, burden, depression, and general health among caregivers of veterans poststroke. The Journal of Neuroscience Nursing, 41(1), 39-52.

Rowe, M.A., McCrae, C.S., Campbell, J.M., et al. (2008). Sleep pattern differences between older adult dementia caregivers and older adult non caregivers using objective and subjective measures. Journal of Clinical Sleep Med- icine. 4(4), 362-369. Available from https://www.ncbi. nIm.nih.gov/pmc/articles/PMC2542494/pdf/jcsm.4.4. 362.pdf.

Spiegel, K., Leproult, R. \& van Cauter, E. (1999). Impact of sleep debt on metabolic and endocrine function. Lancet, 354(0188), 1435-1439.

Stenberg, U., Ruland, C.M. \& Miaskowski, C. (2010). Review of the literature on the effects of caring for a patient with cancer. Psycho-Oncology, 19(10), 1013-1025.

von Känel, R., Dimsdale, J.E., Ancoli-Israel, S., et al. (2006). Poor sleep is associated with higher plasma proinflammatory cytokine interleukin- 6 and procoagulant marker fibrin d-dimer in older caregivers of people with Alzheimer's disease. Journal of the American Geriatrics Society, 54(3), 431-437.

von Känel, R., Ancoli-Israel, S., Dimsdale, J.E., et al. (2010). Sleep and biomarkers of atherosclerosis in elderly Alzheimer caregivers and controls. Gerontology, 56(1), 41-50. Epub ahead of print Dec 3, 2009. Available from https://www.ncbi.nlm.nih.gov/pmc/articles/PMC 2844340/pdf/ger0056-0041.pdf.

Wilcox, S. \& King, A.C. (1999). Sleep complaints in older women who are family caregivers. The Journals of Gerontology. Series B, Psychological Sciences and Social Sciences, 54(4), P189-P198.

Wilson, K.G., Watson, S.T. \& Currie, S.R. (1998). Daily diary and ambulatory activity monitoring of sleep in patients with insomnia associated with chronic musculoskeletal pain. Pain, 75(1), 75-84.

Youngstedt, S.D. \& Kripke, D.F. (2004). Long sleep and mortality: Rationale for sleep restriction. Sleep Medicine Reviews, 8(3), 159-174. 
Table 2. Summary of methodological characteristics of studies includedregarding sleep patternsincaregivers of patients with advancedcancer

\begin{tabular}{|c|c|c|c|c|c|c|}
\hline $\begin{array}{l}\text { Authors, } \\
\text { Year, } \\
\text { Country }\end{array}$ & Design & $\begin{array}{l}\text { Methodo-logical } \\
\text { quality } \\
\text { assessment } \\
\text { scores }\end{array}$ & Objective(s) & Sample & Sleep measures & Sleep outcomes \\
\hline Lee et al, & Descriptive cross- & 33 & Identify sleep disturbances and & $n 1 / 4172 ;$ age $X(S D): 46.1(+12.1)$ & Objective: actigraphy (48 hr) & Objective: \\
\hline 2010 & sectional & & predictors of sleep distur bances & $\mathrm{yx}, 79.1 \%$ temale, $50.6 \%$ spouse & Sübjective -PSQI Chinese & Sleep measure: $X(S D)$ \\
\hline \multirow[t]{12}{*}{ Taiwan } & & & in Taiwanese family caregivers. & of patient; $39.5 \%$ had sleep & version) & Duration of night \\
\hline & & & & disturbances before caregiving; & & sleep: \\
\hline & & & & $77.9 \%$ currently employed & & $266.37 \mathrm{~min}(+139.47)$ \\
\hline & & & & & & $S O L=10.51 \mathrm{~min}$ \\
\hline & & & & & & $(+10.71)$ \\
\hline & & & & & & Wakening during \\
\hline & & & & & & sleep period/epoch: \\
\hline & & & & & & 3.99 times $(2.88)$ \\
\hline & & & & & & Ratio of WASO: \\
\hline & & & & 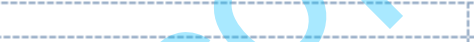 & & $12.53 \%(+9.2)$ \\
\hline & & & & 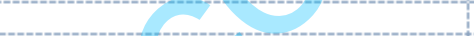 & & Napping during day: \\
\hline & & & & & & $91.55 \mathrm{~min}(+122.01)$ \\
\hline \multirow{7}{*}{$\begin{array}{l}\text { Lee et al, } \\
2014 ; \\
\text { Taiwan }\end{array}$} & Prospective, cross- & 32 & Assess subjective and objective & $n 1 / 4176 ;$ age $X(S D): 59.5(+12.1)$ & Objective - actigraphy $(48 \mathrm{hr})$ & Objective: \\
\hline & sectional & & sleep patterns and identify risk & yx $79.5 \%$ female $51.1 \%$ spouse & Subjective PSQI (Chinese & Sleep measure $X(S D)$ \\
\hline & & & factors for sleep disturbances in & of patient & version) & Duration of night \\
\hline & & & care givers of patients with & $78.4 \%$ living with patient; & & sleep $: 276.04 \mathrm{~min}$ \\
\hline & & & advanced cancer & $40.9 \%$ sleep disturbances & & $(+153.08)$ \\
\hline & & & & before caregiving, $47.7 \%$ & & $\mathrm{SOL}=10.35 \mathrm{~min}$ \\
\hline & & & & currently employed & & $(+10.64)$ \\
\hline & & & & & & $\begin{array}{l}\text { Wakening during } \\
\text { sleep period/epoch: }\end{array}$ \\
\hline & & & & & & 3.94 times $(+2.88)$ \\
\hline & & & & & & Napping during day: \\
\hline & & & & & & $101.45 \mathrm{~min}(+144)$ \\
\hline & & & & & & $\mathrm{SE}: 90.62 \%(+7.03)$ \\
\hline & & & & & & Subjective: \\
\hline & & & & & & PSQI $X(S D)$ \\
\hline & & & & & & Global: $9.05(+4.14)$ \\
\hline & & & & & & Quality: $1.59(+0.79)$ \\
\hline & & & & & & Latency: $1.48(+1.04)$ \\
\hline & & & & & & Duration: 1.48 \\
\hline & & & & & & $(+1.09)$ \\
\hline & & & & & & Habitual sleep: 1.45 \\
\hline & & & & & & $(+1.21)$ \\
\hline & & & & & & Disturbances 1.01 \\
\hline & & & & & & $(+0.41)$ \\
\hline & & & & & & Medications: 0.35 \\
\hline & & & & & & $(+0.86)$ \\
\hline & & & & & & $\begin{array}{l}\text { Daytime dystunction- } \\
1.59(+0.79)\end{array}$ \\
\hline
\end{tabular}




\begin{tabular}{|c|c|c|c|c|c|c|}
\hline $\begin{array}{l}\text { Authors, } \\
\text { Year, } \\
\text { Country }\end{array}$ & Design & $\begin{array}{l}\text { Methodo-logical } \\
\text { quality } \\
\text { assessment } \\
\text { scores }\end{array}$ & Objective(s) & Sample & Sleep measures & Sleep outcomes \\
\hline \multirow{8}{*}{$\begin{array}{l}\text { Delgado- } \\
\text { Guay et al, } \\
2012 \text {, USA }\end{array}$} & Descriptive, & 32 & Examine spiritual aspects of & $n 1 / 443 ;$ median age $52 \mathrm{yr} ; 58 \%$ & Subjective:PSQI & Subjective: \\
\hline & correlational, & & care giver suffering on sleep & spouse of patient & & Group $\mathrm{X}$ expenencing \\
\hline & cross sectional & & & & & spiritual pain?: \\
\hline & & & & & & PSQI median (range) \\
\hline & & & & & & Group 1: no spiritual \\
\hline & & & & & & pain $7(5-9)$ \\
\hline & & & & & & Group 2. spiritual \\
\hline & & & & & & pain $8(4-10)$ \\
\hline \multirow{7}{*}{$\begin{array}{l}\text { Hearson } \\
\text { et al, 2011, } \\
\text { Canada }\end{array}$} & Descriptive, & 31 & Description of sleep in caregivers & $n 1 / 413 ;$ age $X(S D)=58.5(+9.7) \mathrm{yx}$ & Objective actigraphy $(72 \mathrm{hr})$ & Objective $X(S D)$ \\
\hline & exploratory & & of patients with advanced & $54 \%$ spouse of patient $61.5 \%$ & Subjective ESS and PSQI (1 & TST: $6.6 \mathrm{hr}(+1.1)$ \\
\hline & cross sectional & & cancer & employed $69.2 \%$ residing with & mo recall), caregiver & WASO: 41.9 \\
\hline & & & & patient & narratives & $\mathrm{SE}=\frac{-2.85 \%}{\mathrm{~N}}$ \\
\hline & & & & time spent in care giving role: & Sleep log & Interruptions 11.6 \\
\hline & & & & $0-12 \mathrm{mo} 1 / 469.3 \%$ & & $(+3.2)$ \\
\hline & & & & $12-36 \mathrm{~mol} / 4307 \%$ & & Sübjective-ESS $X(S D)$ \\
\hline & & & & 年- & & $\begin{array}{l}8.7(+5.5) \\
38.5 \% \text { showed } \\
\text { excessive daytime } \\
\text { sleepiness scoring } \geq 11 \\
\text { PSQI } X(S D) \\
10.0(3.9) \\
100 \% \text { indicated } \\
\text { moderate to severe } \\
\text { sleep disturbances } \\
\text { scoring .5 } \\
\text { Narrative themes: } \\
\text { 1. Factors contributing } \\
\text { to disturbed sleep } \\
\text { 2. Consequences of } \\
\text { disturbed sleep } \\
\text { 3. Caregiver strate gies } \\
\text { to overcome disturbed } \\
\text { sleep }\end{array}$ \\
\hline \multirow[t]{9}{*}{$\begin{array}{l}\text { Gíbins et al, } \\
2009, \mathrm{UK}\end{array}$} & $\begin{array}{l}\text { Descriptive, } \\
\text { observational, } \\
\text { prospective }\end{array}$ & 25 & $\begin{array}{l}\text { Prevalence study of sleep } \\
\text { disturbances in caregivers of } \\
\text { patients with advanced cancer }\end{array}$ & $\begin{array}{l}n 1 / 460 ; \text { median age } 66 \mathrm{x}, 40 \% \\
\text { female, } 100 \% \text { spouse of patient }\end{array}$ & $\begin{array}{l}\text { Objective continuous } \gamma \text {-day } \\
\text { wrist-actigxaphy. } \\
\text { Subjective: sleep history }\end{array}$ & $\begin{array}{l}\text { Objective: } X \text { over } / \text { days } \\
\text { SE } 1 / 491.07 \% \\
\text { Time awake: } 9 \%\end{array}$ \\
\hline & & & and examine sleep and & & inventory (author & Movement: 37.9 \\
\hline & & & physical/psychological & & constructed baseline. & counts \\
\hline & & & relationships & & Daily sleep diaries for 7 & No of naps: 8.71 \\
\hline & & & & & days, and ESS at day 7 & Length of naps: \\
\hline & & & & & & $8.9 \mathrm{~min}$ \\
\hline & & & & & & Subjective: \\
\hline & & & & & & ESS Median(range) \\
\hline & & & & & & $5.0(0-13)$ \\
\hline
\end{tabular}




\begin{tabular}{|c|c|c|c|c|c|c|}
\hline $\begin{array}{l}\text { Carter, } 2006,2 \\
\text { Tos }\end{array}$ & $\begin{array}{l}\text { Feasibility, experi- } \\
\text { intulfiental, }\end{array}$ & 33 & $\begin{array}{l}\text { Test the feasibility and } \\
\text { effectiveness of a sleep }\end{array}$ & $\begin{array}{l}n 1 / 430 \text { (15 interventional, } 15 \\
\text { control); age } X(\mathrm{SD}): 53(+17)\end{array}$ & $\begin{array}{l}\text { Objective: continuous } 72-\mathrm{hr} \\
\text { wrist actigraphys pre- }\end{array}$ & $\begin{array}{l}\text { Baseline objective: } \\
\text { Intervention group }\end{array}$ \\
\hline & $\begin{array}{l}\text { intervention } \\
\text { control } \\
\text { Prospective }\end{array}$ & & $\begin{array}{l}\text { intervention strategy for } \\
\text { caregivers of patients with } \\
\text { advanced cancer who reported } \\
\text { sleep diffculties }\end{array}$ & $\begin{array}{l}\text { Jx; } 63 \% \text { female: } 57 \% \text { spouse of } \\
\text { patient } \\
100 \% \text { residing with patient; } \\
\text { hours perday spent caregiving } \\
X(S D): 17(+7) \mathrm{hr}\end{array}$ & $\begin{array}{l}\text { intervention, weeks } 3 \text { and } 5 \text {, } \\
\text { and months 2,3, and } 4 \\
\text { Subjective: PSQI (recall: } 1 \\
\text { mo), daily sleep logs (3rd at } \\
\text { each timepoint); pre- } \\
\text { intervention, weeks } 3 \text { and } 5 \\
\text { and months } 2,3 \text {, and } 4\end{array}$ & $\begin{array}{l}X(S D) \\
\text { SOL: } 12.4(+14) \mathrm{min} \\
\text { TST: } 6.4(+1.7) \mathrm{hr} \\
\text { SE: } 89 \%(+8) \\
\text { WASO: } 30(+21) \mathrm{min} \\
\text { PSQI: } 9.9(4.6) \\
\text { Control group } X(S D) \\
\text { SOL: } 11.1(+9) \mathrm{min} \\
\text { TST: } 5.5(+2.1) \mathrm{hr} \\
\text { SE: } 84 \%(+9) \\
\text { WASO: } 45(+28) \mathrm{min} \\
\text { PSQI: } 9.3(5.5) \\
\text { Baseline Subjective: } \\
\text { Intervention Group } \\
\text { X(SD) } \\
\text { SOL: } 27(+36) \mathrm{min} \\
\text { TST: } 5.7(+1.8) \mathrm{hr} \\
\text { SE: } 79 \%(+13.7) \\
\text { PSQI Total } 9.9(+4.6) \\
\text { Control group } \mathrm{X}(\mathrm{SD}) \\
\text { SOL: } 26(+17) \mathrm{min} \\
\text { TST: } 6(+1.7) \mathrm{hr} \\
\text { SE: } 76 \%(+16) \\
\text { PSQI total } 9.3(+5.5)\end{array}$ \\
\hline $\begin{array}{l}\text { Carter, 2003, } \\
\text { USA }\end{array}$ & $\begin{array}{l}\text { Descriptive, } \\
\text { correlational, } \\
\text { prospective }\end{array}$ & 31 & $\begin{array}{l}\text { Describe patterns of depression } \\
\text { and sleep in caregivers of } \\
\text { patients with advanced cancer } \\
\text { over } 10 \text { weeks } \\
\text { Explore feasibility of } \\
\text { quantitative data and compare } \\
\text { to qualitative measures }\end{array}$ & $\begin{array}{l}\text { n1/4 10; } X \text { age } 61 \mathrm{xx} \\
80 \% \text { female; } \\
90 \% \text { spouse of patient } 100 \% \\
\text { residing with patient; } \\
\text { time spent in care giving role } X \\
5.7 \text { months; } \\
\text { hours spent caregiving per day: } \\
X 9.7(10-24) \text { hr }\end{array}$ & $\begin{array}{l}\text { Objective: continuous } 72-\mathrm{hr} \\
\text { wrist actigraphby } \\
\text { - weeks, } 1,5 \text {, and } 10 \\
\text { Subjective: PSQI, (recall } 1 \\
\text { month), } \\
\text { sleep logs (3rd each week) } \\
\text { weeks } 1,5 \text {, and } 10\end{array}$ & $\begin{array}{l}\text { Objective: } \\
\text { Actigraphy X(SD) } \\
\text { Week } 1 \\
\text { Latency: } 42(+38) \mathrm{min} \\
\text { Duration: } 290(+97) \\
\text { min } \\
\text { Efficiency: } 73 \%(+17) \\
\text { Week } 10 \\
\text { Latency: } 40(+42) \mathrm{min} \\
\text { Duration: } 332(+70) \\
\text { min } \\
\text { Efficiency: } 76 \%(+14) \\
\text { Subjective: } \\
\text { PSQI X(SD) } \\
\text { Week 1 } \\
\text { Latency: } 33(+29) \text { min } \\
\text { Duration: } 360(+79) \\
\text { min } \\
\text { Efficiency: } 80 \%(+11) \\
\text { Week 10 } \\
\text { Latency: } 30(+25) \text { min } \\
\text { Duration: } 378(+81) \\
\text { min } \\
\text { Efficiency: } 80 \%(+16)\end{array}$ \\
\hline
\end{tabular}




\begin{tabular}{|c|c|c|c|c|c|c|}
\hline & & Methodo-logical & & & & \\
\hline Authors, & & quality & & & & \\
\hline Year, & & assessment & & & & \\
\hline Country & Design & scores & Objective(s) & Sample & Sleep measures & Sleep outcomes \\
\hline $\begin{array}{l}\text { Carter, 2002, } \\
\text { USA }\end{array}$ & $\begin{array}{l}\text { Descriptive, } \\
\text { exploratory, } \\
\text { cross'sectional }\end{array}$ & 36 & $\begin{array}{l}\text { Describe caregiver depression and } \\
\text { sleep narratives. Compare } \\
\text { descriptions with quantitative } \\
\text { scores of caregivers of patients } \\
\text { with advanced cancer. }\end{array}$ & $\begin{array}{l}31 / 447 ; X \text { age } 53.7 \mathrm{y} ; 87.2 \% \\
\text { female; } 82 \% \text { Caucasian } \\
.50 \% \text { currently employed } \\
100 \% \text { living with patient; } \\
\text { X(SD): Time spent caregiving: } \\
24.3(+29) \text {; hours spent } \\
\text { caregiving per day } 15.8(+8.9) \mathrm{h}\end{array}$ & $\begin{array}{l}\text { Subjective: PSQI (recall } 1 \mathrm{mo} \text { ); } \\
\text { open'ended, one time } \\
\text { interviews. }\end{array}$ & $\begin{array}{l}\text { Subjective: } \\
\text { Global PSQI: } X(S D) \\
\text { Male: } 11.00(+3.71) \\
\text { Female: } 11.53(+4.56) \\
\text { Spouse: } 11.39(+4.25) \\
\text { Non-Spouse: } 11.50 \\
(+4.76) \\
\text { Narrative themes: } \\
\text { 1. Increased } \\
\text { depression with poor } \\
\text { sleep } \\
\text { 2. Decreased QoL as a } \\
\text { consequences of poor } \\
\text { sleep }\end{array}$ \\
\hline $\begin{array}{l}\text { Flaskerud } \\
\text { et al, } 2000 \text {, } \\
\text { USA }\end{array}$ & $\begin{array}{l}\text { Descriptive, } \\
\text { correlational, } \\
\text { cross'sectional }\end{array}$ & 31 & $\begin{array}{l}\text { Describe and compare depressive } \\
\text { symptoms of female caregivers } \\
\text { of AIDS, age related dementia } \\
\text { and advanced cancer on sleep, } \\
\text { depression, anxiety and anger }\end{array}$ & $\begin{array}{l}n 1 / 441 \text {; age } X(S D): \\
51.5(+14.2) \text { yx; } \\
92 \% \text { family member of patient } \\
X(S D) \text { : } \\
\text { time spent caregiving: } 2.0 \\
(+2.4) ; \text { hours spent care giving } \\
\text { per day } 14.9(+8.5) \mathrm{hr}\end{array}$ & $\begin{array}{l}\text { Subjective: PSQI (recall } \\
\text { unknown) }\end{array}$ & $\begin{array}{l}\text { Subjective: } \\
\text { Trouble falling asleep: } \\
46 \% \\
\text { Restless sleep: } 82 \% \\
\text { Trouble falling asleep: } \\
76 \%\end{array}$ \\
\hline $\begin{array}{l}\text { Carter \& } \\
\text { Chang, } \\
\text { 2000, USA }\end{array}$ & $\begin{array}{l}\text { Descriptive, } \\
\text { Correlational, } \\
\text { cross'sectional }\end{array}$ & 36 & $\begin{array}{l}\text { Describe and explore the } \\
\text { relationship of sleep problems } \\
\text { and depression levels in } \\
\text { primary caregivers of patients } \\
\text { with advanced cancer }\end{array}$ & $\begin{array}{l}\text { n } 1 / 451 ; \text { age } X(S D): 53.65(+14.3) \\
\text { xx; } 80.4 \% \text { female; } 60.8 \% \text { spouse } \\
\text { of patient } \\
100 \% \text { residing with patient; } \\
X(S D) \text { : } \\
\text { Time spent care giving: } 24.3(+ \\
29) ; \\
\text { hours spent caregiving per day } \\
15.8(+8.9) \mathrm{hr}\end{array}$ & Subjective: PSQI (recall 1 mo) & $\begin{array}{l}\text { Subjective: } \\
\text { Global PSQI X(SD) } \\
\text { Male: } 11.00(+3.71) \\
\text { Female: } 11.53(+4.56)\end{array}$ \\
\hline
\end{tabular}

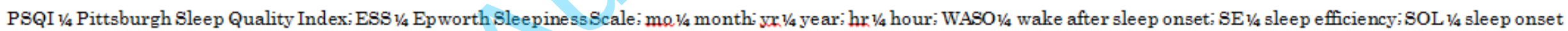
latency, TST $1 / 4$ total sleep time

Normal sleep values

Sleep onset latency, 20 min; total sleep time .420 min; sleep efficiency . $75-80 \%$, WASO (epoch) , 6 times; ratio of wake after sleep onset ,10\%. 


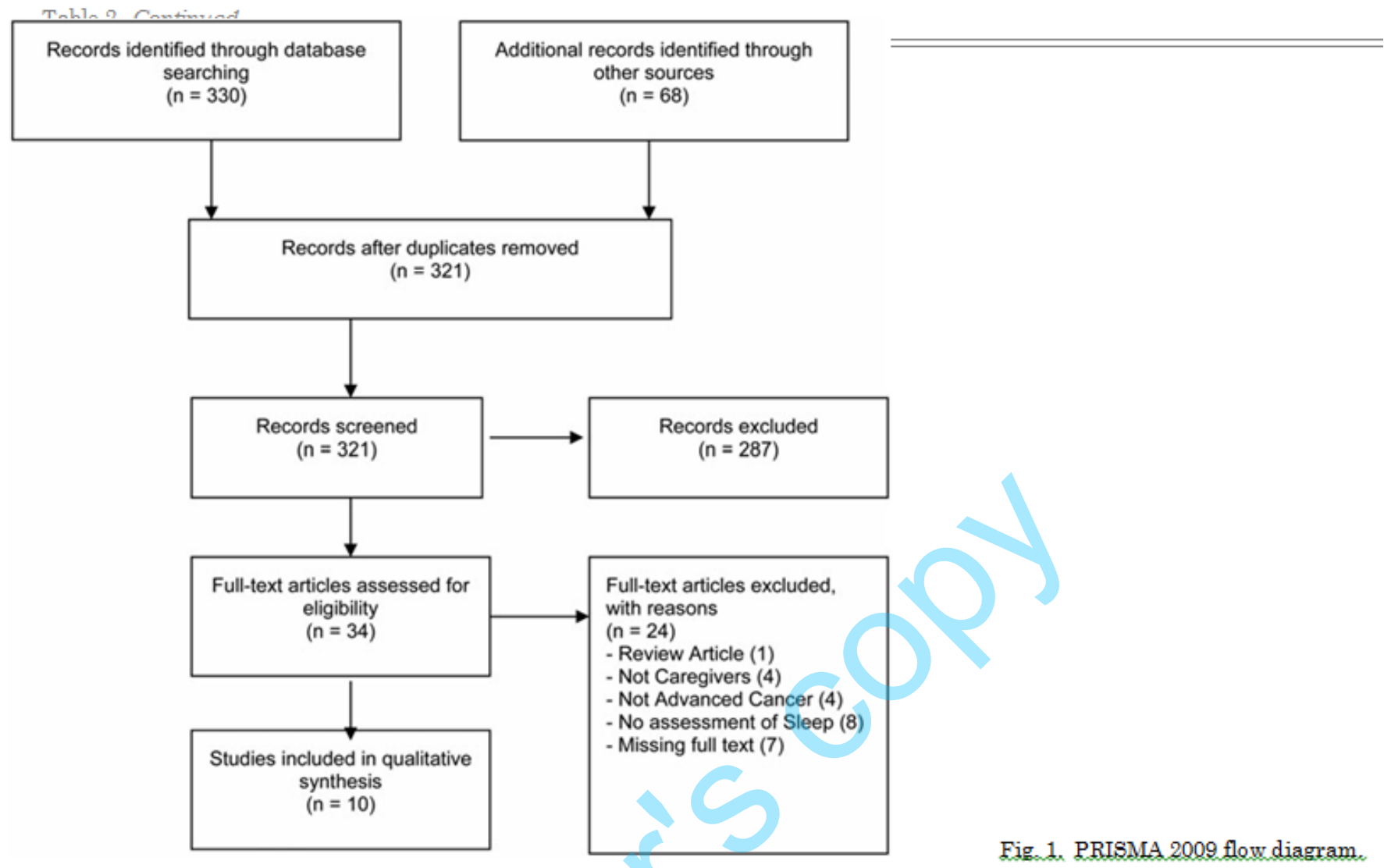




\section{APPENDIX A}

\section{Critical Appraisal Tool}

(see Hawker et al., 2002)

1 Abstract and title: did they provide a clear description of the study?

Good Structured abstract with full information and clear title.

Fair Abstract with most of the information. Poor Inadequate abstract.

Very poor No abstract

2 Introduction and aims: was there a good background and clear statement of the aims of the research?

Good Full but concise background to discussion/ study containing up-to-date literature review and

highlighting gaps in knowledge. Clear statement of aim AND objectives including research questions. Some background and literature review: research questions outlined.

Poor Some background but no aim/objectives/ questions, OR aims/objectives but inadequate background.

Very poor No mention of aims/objectives: no background or literature review.

3 Method and data: is the method appropriate and clearly explained?

Good Method is appropriate and described clearly (e.g., questionnaires included); clear details of data collection and recording.

Fair Method appropriate; description could be better. Data described.

Poor Questionable whether method is appropriate: method described inadequately. Little description of data.

Very poor No mention of method AND/OR method inappropriate AND/OR no details of data.

4 Sampling: was the sampling strategy appropriate to ad- dress the aims?

Good Details (age/gender/race/context) of who was studied and how they were recruited. Why was this group targeted? Sample size was justified for the study. Response rates shown and explained.

Fair Sample size justified. Most information given, but some missing.

Poor Sampling mentioned but few descriptive details.

Very poor No details of sample.

5 Data analysis: was the description of the data analysis sufficiently rigorous?

Good Clear description of how analysis was done.

Qualitative studies: description of how themes derived/respondent validation or triangulation.

Quantitative studies: reasons for tests selected; hypothesis-driven/ numbers add up/statistical significance discussed.

Fair Qualitative: descriptive discussion of analysis: quantitative.

Poor Minimal details about analysis. Very poor No discussion of analysis.

6 Ethics and bias: have ethical issues been addressed? What has necessary ethical approval gained? Has the relationship between researchers and participants been adequately considered?

Good ethics: Where necessary issues of confidentiality, sensitivity, and consent were addressed. Bias: researcher was reflexive and/or aware of own bias.

Fair Lip service was paid to above (i.e., these issues were acknowledged).

Poor Brief mention of issues. Very poor No mention of issues. 
7 Results: Is there a clear statement of the findings?

Good Findings explicit, easy to understand, and in logical progression. Tables, if present, are explained in text. Results relate directly to aims. Sufficient data are presented to support findings.

Fair Findings mentioned but more explanation could be given. Data presented relate directly to results.

Poor Findings presented haphazardly, not explained, and do not progress logically from results.

Very poor Findings not mentioned or do not relate to aims.

8 Transferability or generalizability: are the findings of this study transferable (generalizable) to a wider popula- tion?

Good Context and setting of the study is described sufficiently to allow comparison with other contexts and settings, plus high score on question 4 (sampling).

Fair Some context and setting described, but more needed to replicate or compare the study with others, PLUS fair score or higher on question 4.

Poor Minimal description of context/setting. Very poor No description of context/setting.

9 Implications and usefulness: how important are these findings to policy and practice?

Good Contributes something new and/or different in terms of understanding/ insight or perspective. Suggests ideas for further research. Suggests implications for policy and/or practice.

Fair Two of the above (state what is missing in comments).

Poor Only one of the above. Very poor None of the above. 


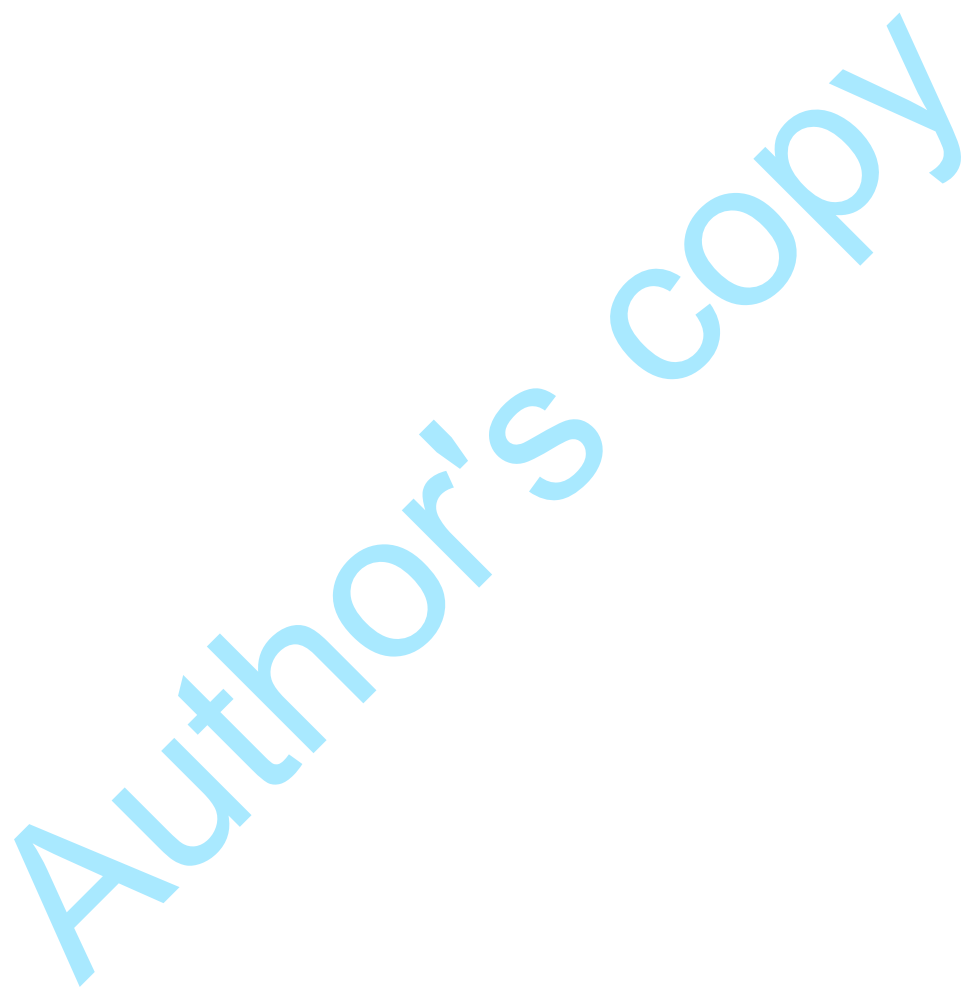

